\title{
Design Optimization of the Box Section of the Single-girder Bridge Crane by Generalized Reduced Gradient Algorithm
}

\author{
Goran Pavlović ${ }^{*}$, Aleksandar Stepanović ${ }^{1}$, Jelena Vidaković1 ${ }^{\text {, Mile Savković }}{ }^{2}$, Nebojša Zdravković $^{2}$ \\ ${ }^{1}$ Lola Institute, Belgrade (Serbia) \\ ${ }^{2}$ Faculty of Mechanical and Civil Engineering in Kraljevo, Kraljevo (Serbia)
}

The paper considers the problem of design optimization of the box section of the single-girder bridge crane. Reduction of the girder mass is set as the objective function. The algorithm of generalized reduced gradient (GRG2 algorithm) was used as the methodology for determination of optimum geometrical parameters of the box section. The criteria of permissible stresses, local stability of plates, lateral stability of the girder, static deflection, dynamic stiffness and production feasibility (distance between the webs) were applied as the constraint functions. The optimization of the box section geometrical parameters was conducted for payloads and spans typical for single-girder bridge cranes.

Keywords: box section, single-girder bridge crane, GRG2 algorithm, optimization

\section{INTRODUCTION}

Optimization is the most convenient procedure for finding the values of variables within given constraints set, while in accordance with an objective function. It usually refers to design that enables the decrease of total production cost, achieves the highest possible reliability or fulfils any other specific requirements.

The main task during the design of bridge crane structure is to determine optimum dimensions for box section of main girder. Since the share of main girder mass in overall mass of bridge crane is the greatest one, it is very important to optimize it in order to reduce total cost of production. Many authors studied the optimization of cross-sections and their geometric parameters to decrease mass of structure and reduce overall production cost ([1], [2], [3], [4], [5], [6], [7], [8], [9], [10], [13], [16], [17], [18], [19], [20], [21], [22] and [24]).

The optimization of the welded box girder [9] showed that proper placement of longitudinal stiffeners may result in savings up to the amount of $18-21 \%$.

The optimization of the box section of the main girder of the bridge crane was also carried out in [19], where during the optimization the constant height of the girder $h$ was adopted, and the other geometrical parameters of the cross section were changed. In this way was shown that the mass can be reduced even up to 20.6, i.e. $8.46 \%$ without any risky exceeding of the permissible stress.

It can be noticed that optimization is performed either analytically or by means of the finite element method. The finite element method is suitable because a lot of variables are varied. The advantage of analytical methods is that they provide functional dependences of optimization results so that the analysis can define the influence of certain parameters on the reduction of mass.

Most authors set permissible stress or two constraint functions: permissible stress and permissible deflection as the constraint function. The criterion of lateral stability has lately been increasingly applied as the constraint function ([5], [9], [10], [16], [17], [20], [22] and [24]).
Beside analytical methods and finite element method (FEM), numerical methods are increasingly used within optimization recently. Thus, the usage of GRG algorithm can be seen in [7] where mass was reduced by $7,44 \%$ relative to start value. Also, the same algorithm is used in [24], where the mass of double-girder bridge crane was optimized for typical payloads and spans.

Having in mind previously stated results and conclusions, the objective of this paper is to define optimum values for box section geometric parameters of single-girder bridge crane, which would lead to mass reduction.

\section{GRG2 ALGORITHM}

This procedure is the one from a class of technique called reduced gradient or projections gradient which is based on the method for linear constraints, expanded for nonlinear constraints. The variables are set in such way that active constraints are still satisfied, while the procedure is being repeatedly applied from one point to another one. The idea for this algorithm came from Wilde and Beightler (1967) as method of constrained derivatives, Volfe (1963) called it the method of reduced gradient and, finally, Abadie and Carpenter (1969) named it as the method of generalized reduced gradient - generalized gradient method.

If the model and constraints are linear, this procedure is simplex method of linear programming, and if there are no constraints then it is a gradient search.

GRG method is based upon elimination of variables by using constraints equality. The idea is to convert the constraints problem into one without constraints by direct substitution. GRG method uses the approach to find improved direction for the model while satisfying the constraints equations.

Microsoft Excel Solver uses GRG2 algorithm for optimization of nonlinear problems. This algorithm is developed by Leon Lasdon from University of Texas and Alan Varen from University of Cleveland (Microsoft Inc. 2011). 


\section{MATHEMATICAL FORMULATION OF THE OPTIMIZATION PROBLEM}

Such nonlinear optimization problem can be written by the following mathematical formulation: minimize

$$
f(\boldsymbol{X})
$$

subject to

$$
g_{i}(\boldsymbol{X}) \leq 0, i=1, \ldots, m
$$

and

$$
l_{i} \leq X_{i} \leq u_{i}, \quad i=1, \ldots, n
$$

where:

$f(\boldsymbol{X})$ - the objective function,

$g_{i}(\boldsymbol{X}) \leq 0, i=1, \ldots, m$ - the constraint functions,

$l_{i}, u_{i}$ - lower, i.e. upper boundary, where $u_{i}>l_{i}$.

Here $\boldsymbol{X}=\left\{x_{1}, \ldots, x_{n}\right\}^{T}$ represents the design vector made of $n$ design variables. Design variables are the values that should be defined during the optimization procedure. Each design variable is defined by its upper and lower boundaries.

The objective and constraint functions are presented in the next chapter.

\section{OBJECTIVE AND CONSTRAINT FUNCTIONS}

\subsection{Objective function}

The model is presented in Fig. 1.

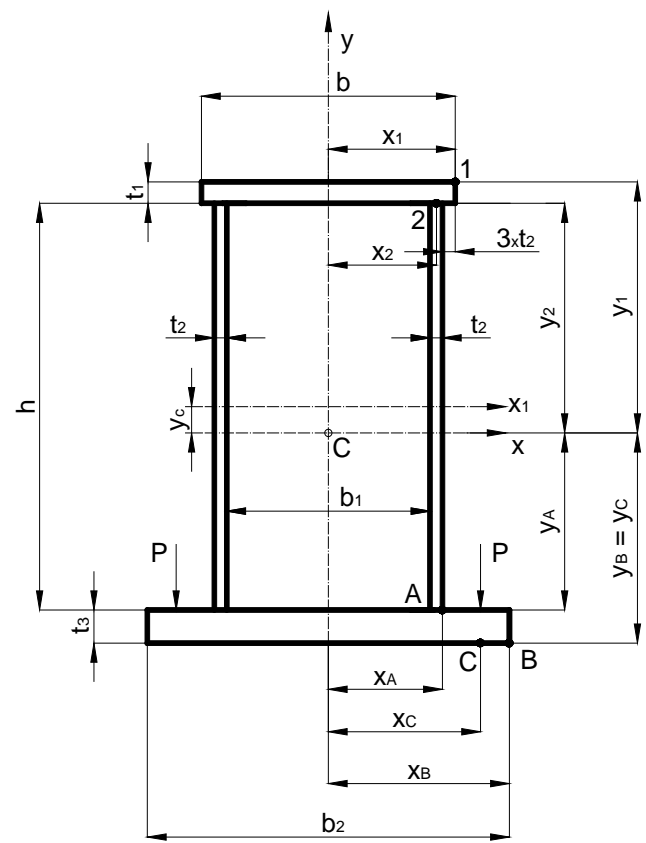

Figure 1. The box section of the single-girder bridge crane

The objective function is represented by the area of the cross-section of the box girder. The paper treats all geometric variables:

$$
\left(h, b, b_{1}, b_{2}, t_{1}, t_{2}, t_{3}\right)
$$

where:

$h$ - web height,

$b$ - top flange width,

$b_{1}$-distance between webs,

$b_{2}$ - bottom flange width,

$t_{1}$ - top flange thickness,

$t_{2}$ - web thickness, $t_{3}$ - bottom flange thickness.

The vector of the given parameters is:

$$
\vec{x}=\left(M_{c v}, M_{c h}, Q, L, E, v, k_{a}, \ldots\right)
$$

where:

$M c v$ and Mch are the bending moments in the vertical and horizontal planes,

$Q$ - the carrying capacity of the crane,

$L$ - the span of the crane,

$E$ - the module of elasticity of the main girder material,

$v$ - Poisson coefficient,

$k_{a}$ - the dynamic coefficient of crane load in the horizontal plane, [11].

The area of the cross section, i.e. the objective function, is:

$$
A=2 \cdot h \cdot t_{2}+b \cdot t_{1}+b_{2} \cdot t_{3}
$$

Determination of other section properties of box section in Fig. 1 is well known.

\subsection{Constraint functions}

All conditions related to check of cranes and required by domestic regulations are taken into consideration as constraint functions, i.e.: permissible stresses, local stability of plates, girder lateral stability, static and dynamic stiffness and production feasibility (distance between the webs). In addition, the minimum plate thickness is taken into consideration.

It should be pointed out that the local stresses, which occur due to the action of wheel pressure on bottom flange, are taken into account within permissible stress criterion. These local stresses in characteristic points are determined according Mendel [15].

\subsubsection{Strength criterion} girder.

Strength check is conducted in specific points of

Actual stress $\sigma_{r}$ has to be lower than critical stress $\sigma_{k}$, which depends on load case:

$$
\begin{gathered}
\sigma_{r} \leq \sigma_{k} \\
\sigma_{k 1}=R_{e} / v_{1} \\
\sigma_{k 2}=R_{e} / v_{2}
\end{gathered}
$$

where:

$R_{e}$ - minimum yield stress,

$v_{1}$ - the factored load coefficient for load case 1 ,

$v_{2}$ - the factored load coefficient for load case 2 ,

$\sigma_{k 1}$ - critical stress for load case 1 ,

$\sigma_{k 2}$ - critical stress for load case 2 .

Constraint function has the following form:

$$
g_{1}=\sigma_{r}-\sigma_{k} \leq 0
$$

The highest stresses occur at the middle of the span, where maximum values of bending moments are as follows:

$$
\begin{gathered}
M_{V I}=M_{c v}+c_{1} \cdot A \\
M_{H I}=M_{c h}+k_{a} \cdot c_{1} \cdot A
\end{gathered}
$$

where:

$M_{V I}$ and $M_{H I}$ - maximum bending moments in the vertical and horizontal plane,

$c_{1}$ - weight per unit of length of the girder. 
Strength criterion must be fulfilled at all characteristic points.

Point 1:

Equivalent stress in point 1:

$$
\sigma_{1, u}=\sigma_{z V 1}+\sigma_{z H 1}=\frac{M_{V I}}{W_{x \mathbf{l}}}+\frac{M_{H I}}{W_{y 1}} \leq \sigma_{k 1}
$$

where:

$W_{x \mathbf{l}}, W_{\mathbf{y} \mathbf{l}}$ - section moduli for point 1 .

Point 2:

Normal stress in point 2:

$$
\sigma_{z 2}=\sigma_{z V 2}+\sigma_{z H 2}=\frac{M_{V I}}{W_{x 2}}+\frac{M_{H I}}{W_{y 2}}
$$

where:

$W_{x 2}, W_{y 2}$ - section moduli for point 2 .

Shear stress in point 2:

$$
\tau=\frac{F_{t} \cdot S_{x 2}}{2 \cdot t_{2} \cdot I_{x}}
$$

where:

$F_{t}$ - shear force,

$S_{x 2}$ - static moment of area for point 2,

$I_{\boldsymbol{x}}$ - moment of inertia about $x$ axis.

Equivalent stress in point 2:

$$
\sigma_{2, u}=\sqrt{\sigma_{z 2}^{2}+3 \cdot \tau^{2}} \leq \sigma_{k 1}
$$

Point B:

Equivalent stress in point B:

$$
\sigma_{B, u}=\sigma_{z V B}+\sigma_{z H B}=\frac{M_{V I}}{W_{x B}}+\frac{M_{H I}}{W_{y B}} \leq \sigma_{k 1}
$$

where:

$W_{x B}, W_{x B}$ - section moduli for point B.

\section{Point A:}

In this point, additionaly, wheel pressure causes some local stresses.

These local stresses depend on coefficients depicted in Fig. 3. Their values depend on ratio $c / a$, also affected by trolley dimensions (Fig. 2).

Fig. 2 shows the distance $(c)$ between the direction of wheel pressure force $(P)$, acting on bottom flange, from the web.

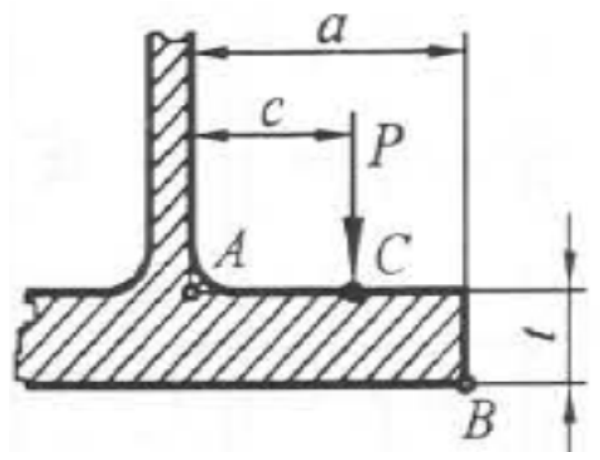

Figure 2. Position of wheel pressure force in relation to the web

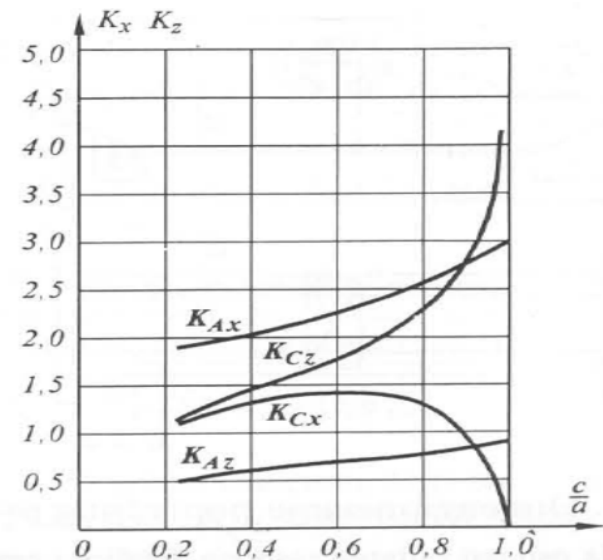

Figure 3. Wheel pressure coefficients are:

Local stresses in point A due to wheel pressure

$$
\begin{aligned}
& \sigma_{x, A}^{P}=K_{A x} \cdot \frac{P}{t_{3}^{2}} \leq \sigma_{k 1} \\
& \sigma_{z, A}^{P}=K_{A z} \cdot \frac{P}{t_{3}^{2}} \leq \sigma_{k 1}
\end{aligned}
$$

where:

$P$ - wheel pressure force.

Normal stress in point A for $z$ direction is:

$$
\sigma_{z A}=\sigma_{z, A}^{P}+\sigma_{z V A}+\sigma_{z H A}=K_{A z} \cdot \frac{P}{t_{3}^{2}}+\frac{M_{V I}}{W_{x A}}+\frac{M_{H I}}{W_{y A}}
$$

where:

$W_{x A}, W_{y A}$ - section moduli for point A.

Equivalent stress in point $\mathrm{A}$ is:

$$
\sigma_{A, u}=\sqrt{\sigma_{z A}^{2}+\sigma_{x, A}^{P}-\sigma_{z A} \cdot \sigma_{x, A}^{P}} \leq \sigma_{k 1}
$$

Point C (under wheel pressure force $\mathrm{P}$ ):

Local stresses in point $\mathrm{C}$ due to wheel pressure are:

$$
\begin{aligned}
& \sigma_{x, C}^{P}=K_{C x} \cdot \frac{P}{t_{3}^{2}} \leq \sigma_{k 1} \\
& \sigma_{z, C}^{P}=K_{C z} \cdot \frac{P}{t_{3}^{2}} \leq \sigma_{k 1}
\end{aligned}
$$

Normal stress in point $\mathrm{C}$ for $\mathrm{z}$ direction is:

$$
\sigma_{z C}=\sigma_{z, C}^{P}+\sigma_{z V C}+\sigma_{z H C}=K_{C z} \cdot \frac{P}{t_{3}^{2}}+\frac{M_{V I}}{W_{x C}}+\frac{M_{H I}}{W_{y C}}
$$

where:

$W_{x c}, W_{y c}$ - section moduli for point C.

Equivalent stress in point $\mathrm{C}$ is:

$$
\sigma_{C, \mu}=\sqrt{\sigma_{z C}^{2}+\sigma_{x, C}^{P}-\sigma_{z C} \cdot \sigma_{x, C}^{P}} \leq \sigma_{k 2}
$$

\subsubsection{Local stability of plates}

Local stability check is done in the same manner for both the flange and web plates, according to actual standard JUS U.E7.121/86, [12].

The paper considers the case with one row of horizontal stiffeners, along with vertical stiffeners being placed at the distance of $a_{1}=2 h$, [15].

The check is done for the top flange under compression, and also for region 1 and 2 of the web plate, since there is one row of horizontal stiffeners (Fig.6). 


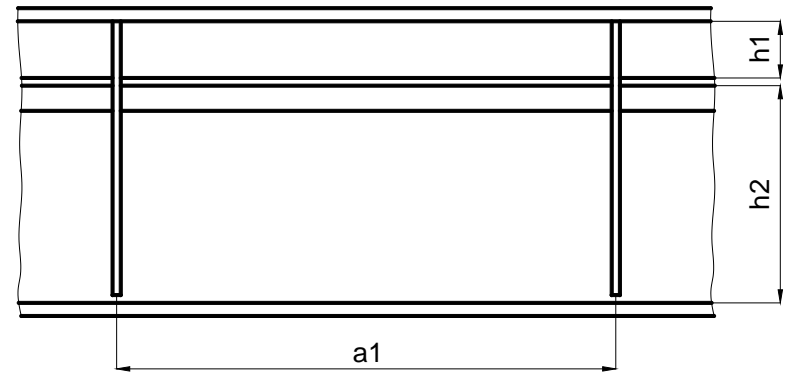

Figure 4. Stiffeners of the box girder

To satisfy the stability condition it must be:

$$
\sigma_{\max } \leq \sigma_{u x} \leq \sigma_{v}
$$

where:

$\sigma_{\max }$ - the maximum pressure stress,

$\sigma_{u x}$ - buckling stress limit [12],

$\sigma_{v}$ - yield stress, [12].

Constraint function has the form:

$$
g_{2}=\sigma_{\max }-\min \left(\sigma_{u x}, \sigma_{v}\right) \leq 0
$$

Flange plate check:

To satisfy this stability it must be:

$$
\sigma_{1 p} \leq \sigma_{u x p} \leq \sigma_{v p}
$$

where:

$$
\sigma_{1 p}=-v_{1} \cdot\left(\sigma_{z V 1}+\sigma_{z H 2}\right)
$$

$\sigma_{\text {uxp }}$ - buckling stress limit for the flange plate [12],

$$
\sigma_{v p}=\frac{\pi^{2} \cdot E}{12 \cdot\left(1-v^{2}\right)} \cdot\left(t_{1} / b_{1}\right)^{2}
$$

All included parameters are calculated in compliance with mentioned standard.

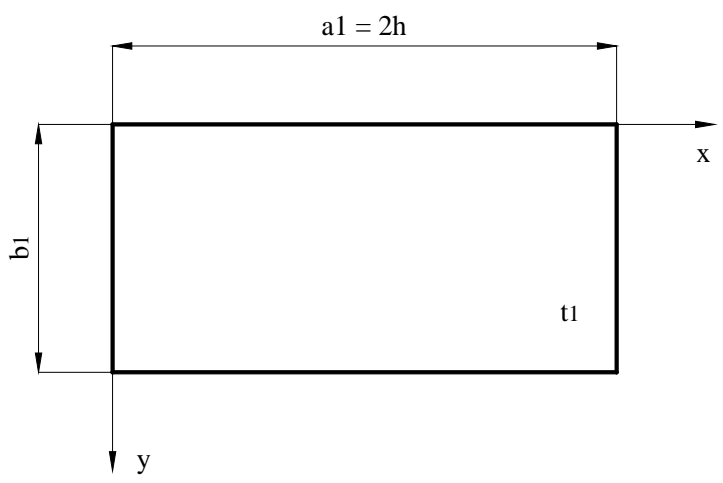

Figure 5. Flange plate dimensions

Web plate check:

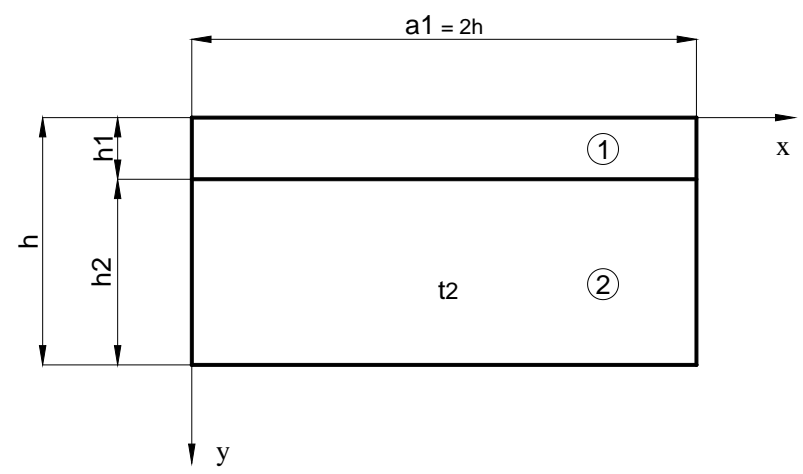

Figure 6. Region 1 and 2 of the web
Region 1:

To satisfy the stability condition it must be:

$$
\sigma_{1} \leq \sigma_{u \times 1} \leq \sigma_{v 1}
$$

where:

$$
\sigma_{1}=-v_{1} \cdot\left(\sigma_{z V 2}+\sigma_{z H 2}\right)
$$

$\sigma_{u \times 1}$ - buckling stress limit for the web plate, region 1 , [12],

$$
\sigma_{v 1}=\frac{\pi^{2} \cdot E}{12 \cdot\left(1-v^{2}\right)} \cdot\left(t_{2} / h_{1}\right)^{2}
$$

where:

$h_{1}$ - region height 1 .

All included parameters are calculated in compliance with mentioned standard.

Region 2:

To satisfy the stability condition it must be:

$$
\sigma_{2} \leq \sigma_{u \times 2} \leq \sigma_{v 2}
$$

where:

$$
\sigma_{2}=-v_{1} \cdot\left(\sigma_{z V 2} \cdot \frac{y_{1}-t_{1}-h_{1}}{y_{1}-t_{1}}+\sigma_{z H 2}\right)
$$

$\sigma_{u x 2}$ - buckling stress limit for the web plate, region 2, [12],

$$
\sigma_{v 2}=\frac{\pi^{2} \cdot E}{12 \cdot\left(1-v^{2}\right)} \cdot\left(t_{2} / h_{2}\right)^{2}
$$

where:

$h_{2}$ - region height 2 .

All included parameters are calculated in compliance with mentioned standard.

\subsubsection{Lateral stability of the girder}

Safety check for lateral stability of the girder is done in compliance with the standard JUS U.E7.101/91, JUS U.E7.081/86, [12] for box girders. So, it has to be fulfilled:

$$
\begin{gathered}
\sigma_{z V 1}=M_{V I} / W_{x 1} \leq \sigma_{k 3} \\
\sigma_{k 3}=\chi \cdot R_{e} / v_{I}
\end{gathered}
$$

where:

$\chi$ - nondimensional buckling coefficient, defined according [12].

Constraint function reads:

$$
g_{3}=\sigma_{z V 1}-\sigma_{k 3} \leq 0
$$

\subsubsection{Static deflection}

To determine stiffness, it is necessary to analyse static deflection of main girder in vertical plane.

$$
f=\frac{F_{1} \cdot L^{3}}{48 \cdot E \cdot I_{x}} \cdot\left[1+\alpha \cdot\left(1-6 \cdot \beta^{2}\right)\right] \leq f_{\text {dop }}=K \cdot L
$$

where:

$f$ - actual deflection in vertical plane,

$f_{\text {dop }}$ - permissible deflection in vertical plane,

$F_{1}$ - force acting upon girder beneath the trolley wheel,

$K$ - the coefficient which depends on the classification class and the manner the crane is operated [15], $\alpha=1, \beta=d / L$, - the coefficient according to [15], 
$\boldsymbol{d}$ - distance between trolley wheels (depends on load capacity $Q$ ), [15].

Constraint function has the form:

$$
g_{4}=f-f_{d o p} \leq 0
$$

\subsubsection{Dynamic stiffness of the girder}

To determine dynamic stiffness, it is necessary to analyse the vertical oscillation of main girder with the payload.

The oscillation model consists of the beam and lumped mass in the middle of the span (Fig. 7).

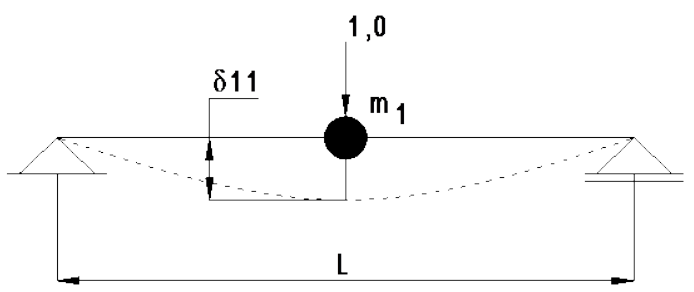

Figure 7. The model of oscillation of the main girder with concentrated mass of the load and the trolley

The mass $\boldsymbol{m}_{\mathbf{1}}$, lumped at the midpoint of the beam, is determined as:

$$
m_{1}=Q+m_{k}+0,486 \cdot m_{m}
$$

where:

$Q+\boldsymbol{m}_{\boldsymbol{k}}$ - the payload and the trolley mass,

$\mathbf{0}, \mathbf{4 8 6} \cdot \boldsymbol{m}_{\boldsymbol{m}}$ - the reduced distributed mass of the girder at span midpoint for the assumed deflection function of the adopted discrete dynamic model, [14].

The time of damping of oscillation is determined from the expression:

$$
T=3 \cdot \tau / \gamma_{d} \leq T_{d}
$$

where:

$$
\tau=2 \cdot \pi \cdot \sqrt{\delta_{11} \cdot m_{1}}
$$

$\tau$ - the period of oscillation $(s)$,

$$
\delta_{11}=\frac{1,0 \cdot L^{3}}{48 \cdot E \cdot I_{x}}
$$

$\delta_{11}$ - the deflection of the girder caused by the action of the unit force,

$T_{d}$ - the permissible time of damping of oscillation (s), which depends on the purpose of the crane, [15],

$\gamma_{d}$ - the logarithmic decrement which shows the rate of damping of oscillation, which depends on the ratio between the height of the girder $h$ and the span $L$, [15].

Constraint function is:

$$
g_{5}=T-T_{d} \leq \mathbf{0}
$$

\section{NUMERICAL PRESENTATION OF OBTAINED RESULTS}

The optimization is done by generalized gradient method (GRG2 algorithm) and using Solver tool from Analysis module of Excel software.

Variable parameters are section height and width and plates thicknesses, (4). All constraint functions stated in previous chapter are taken into analysis.
The case with one row of longitudinal stiffeners is analysed. Also, the longitudinal stiffeners are adopted to be placed at the distance of $h / 4$, according the recommendations [15].Minimum plate thickness is adopted to be $5 \mathrm{~mm}$, which is also the constraint function. In addition, as one more constraint function, minimum distance between the web plates is taken to be $b_{2, \min }=25$ $\mathrm{cm}$. The analysis was performed for the classification class 2 , which is most frequently used in practice. Thus, specific input parameters are taken in accordance with this class. Also, a case with floor-operated crane is considered.

For classification class 2 and floor-operated crane, the coefficient of permissible deflection takes value $K=1 / 500$, [15].Within dynamic stiffness criteria, the permissible time of damping of oscillation for classification class 2 is $T_{d}=15 s$, [15].

Typical spans between $15 \mathrm{~m}$ and $25 \mathrm{~m}$, as well as the typical load capacities from $5 t$ and $20 t$ are used in this analysis.

The data for trolleys are taken from manufacturer SWF Krantechnik (Fig. 8 and Fig. 9). In order to simultaneously present variations of parameters in relation to load capacities, eight-wheel trolleys are used [23]. Following table shows dimensions and masses of trolleys for typical load capacities, which are significant for the analysis.

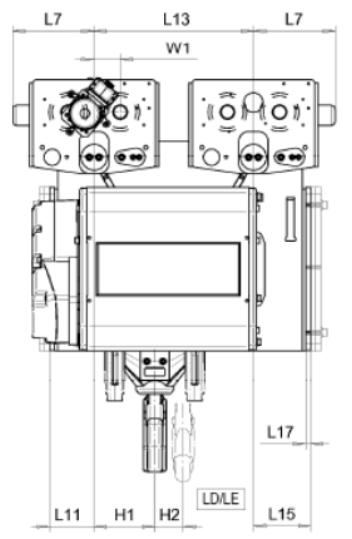

Figure 8. Trolley with hoist

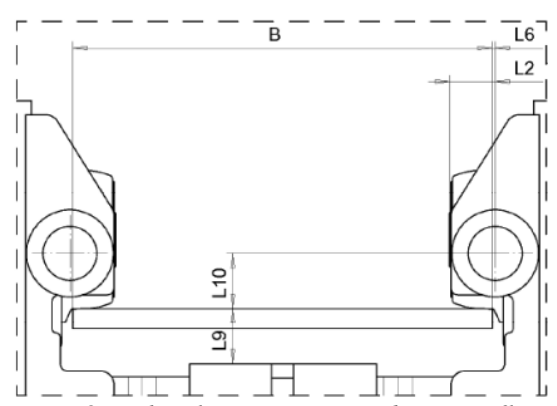

Figure $\overline{9}$. Wheels position on bottom flange

Table 1. Trolley and hoist data

\begin{tabular}{|c|c|c|c|c|c|}
\hline $\begin{array}{c}Q \\
(t)\end{array}$ & $\begin{array}{c}m_{k} \\
(\mathrm{~kg})\end{array}$ & $\begin{array}{c}L_{13} \\
(\mathrm{~mm})\end{array}$ & $\begin{array}{l}W_{1} \\
(\mathrm{~mm})\end{array}$ & $\begin{array}{l}L_{2} \\
(\mathrm{~mm})\end{array}$ & $\begin{array}{l}L_{6} \\
(\mathrm{~mm})\end{array}$ \\
\hline 5 & 790 & 494 & 80,6 & 33 & 2 \\
\hline 6,3 & 790 & 494 & 80,6 & 33 & 2 \\
\hline 8 & 790 & 494 & 80,6 & 33 & 2 \\
\hline 10 & 790 & 494 & 80,6 & 33 & 2 \\
\hline 12,5 & 1000 & 600 & 97,5 & 42 & 2 \\
\hline 16 & 1100 & 600 & 97,5 & 42 & 2 \\
\hline 20 & 1100 & 600 & 97,5 & 42 & 2 \\
\hline
\end{tabular}


Depending on trolley dimensions, coefficients for local stresses caused by wheel pressure take following values:

$K_{A x}=2,4, \quad K_{A z}=0,74, \quad K_{C x}=1,35, \quad K_{C z}=2,0, \quad$ for load capacities from $5 t$ to $10 t$,

$K_{A x}=2,5, \quad K_{A z}=0,75, \quad K_{C x}=1,3, \quad K_{C z}=2,15$, for load capacities from $12,5 t$ to $20 t$,

Steels S235 and S355 are used as girder materials.

Optimization, i.e. the procedure for determination of optimum dimensions of box section by mentioned method, is conducted by algorithm presented in Fig. 10.

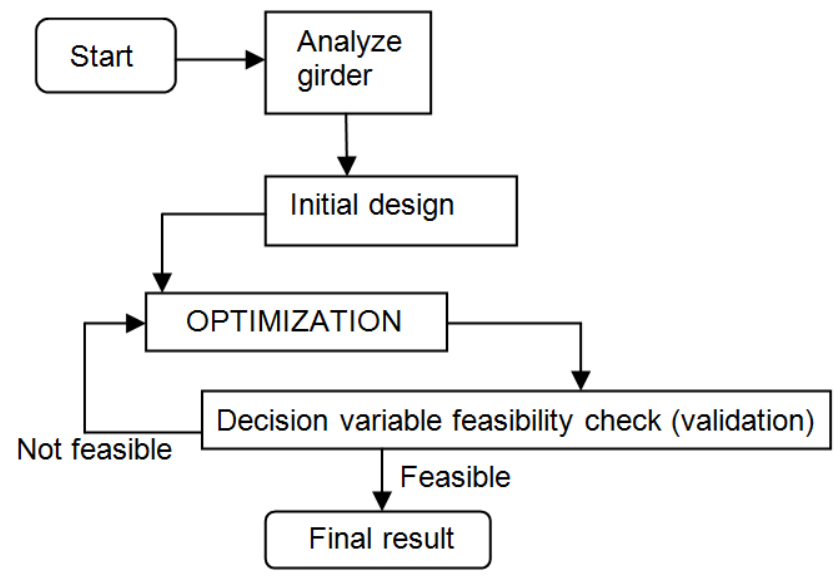

Figure 10. Optimization algorithm

The results are presented for typical spans, load capacities and selected material (Figs. 11-22). Span is assigned to abscissa, while the optimization result is assigned to ordinate.

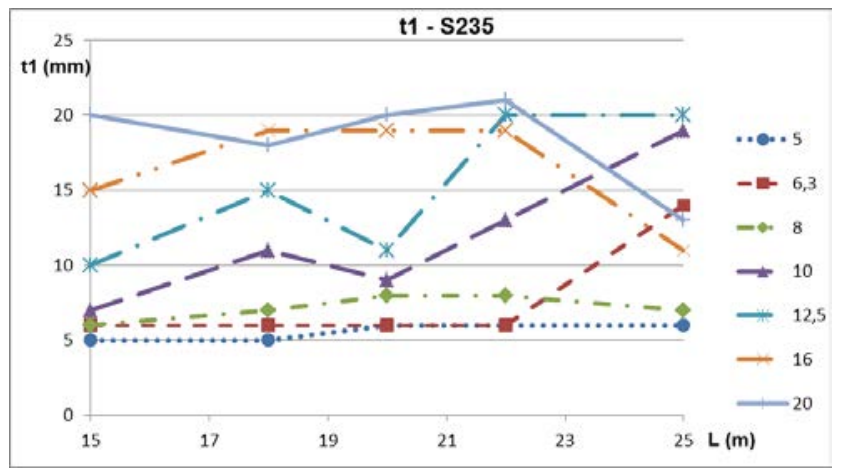

Figure 11. Optimization result for $t_{1}-S 235$

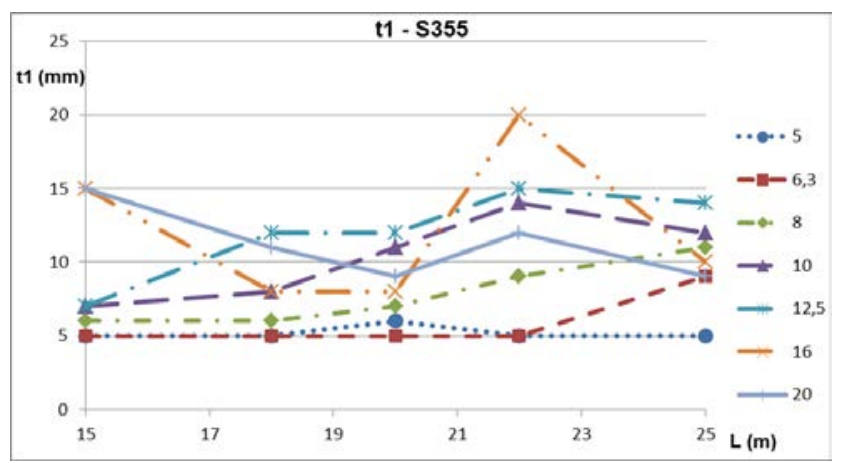

Figure 12. Optimization result for $t_{1}-S 355$

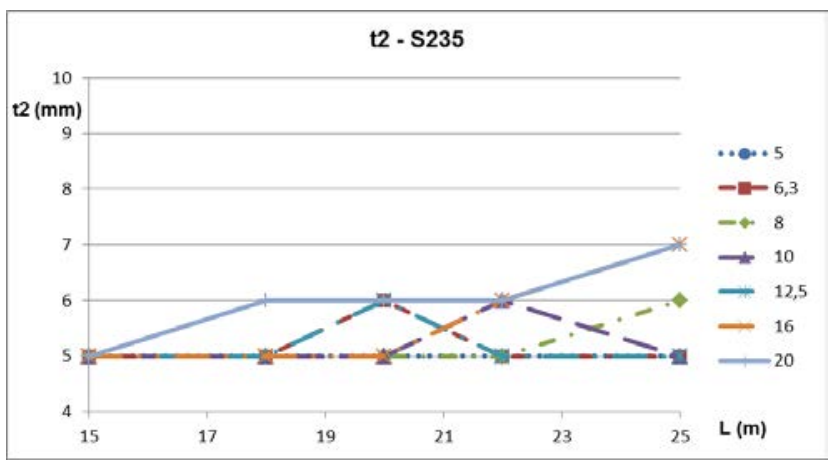

Figure 13. Optimization result for $t_{2}-S 235$

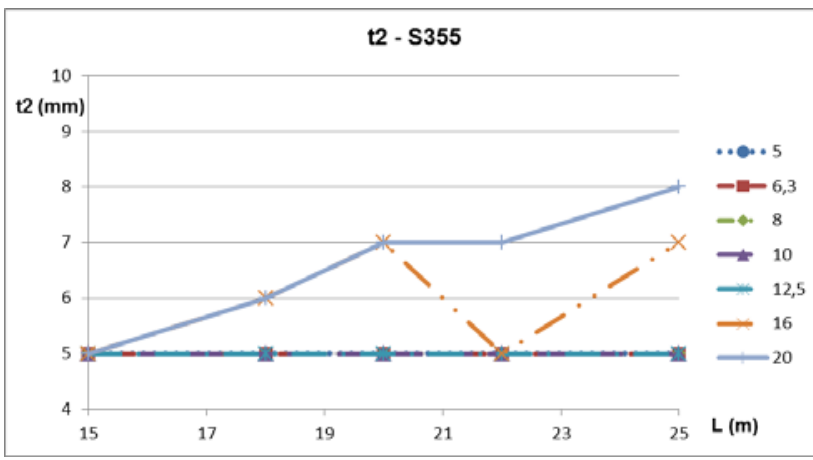

Figure 14. Optimization result for $t_{2}-S 355$

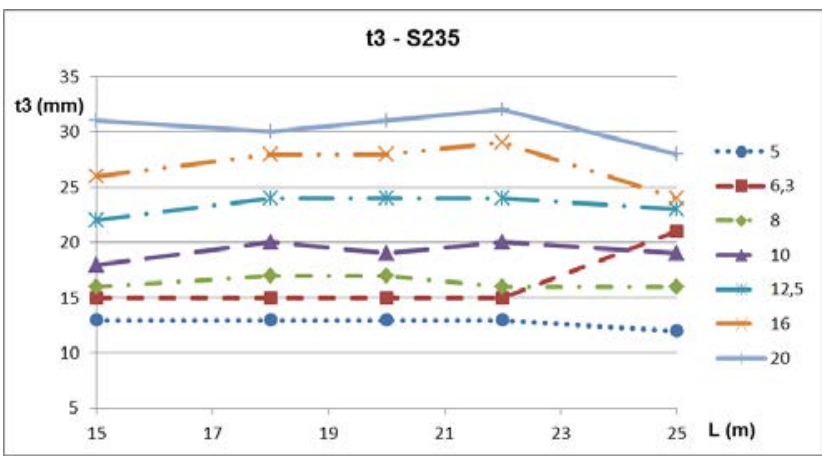

Figure 15. Optimization result for $t_{3}-S 235$

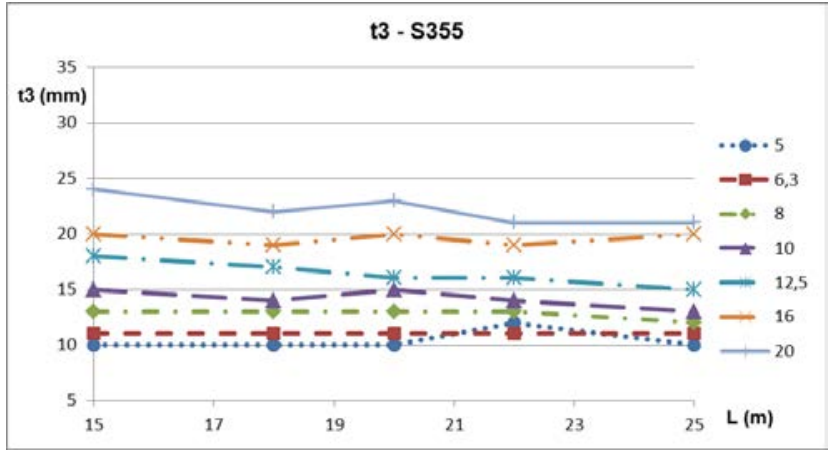

Figure 16. Optimization result for $t_{3}-S 355$

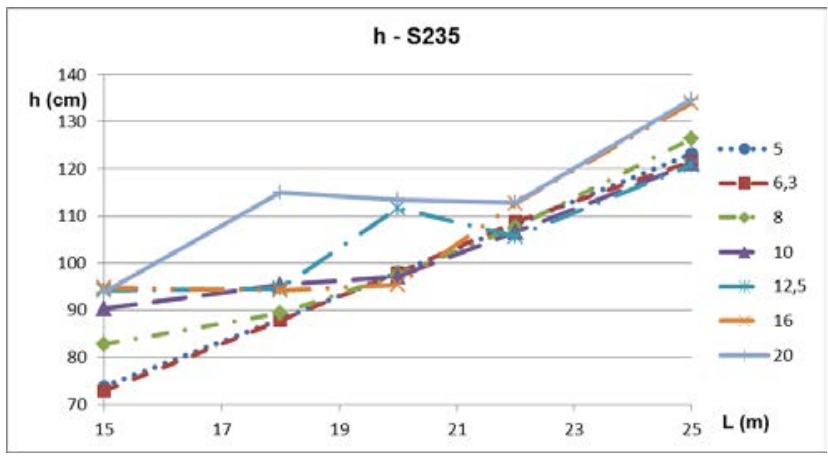

Figure 17. Optimization result for $h-S 235$ 


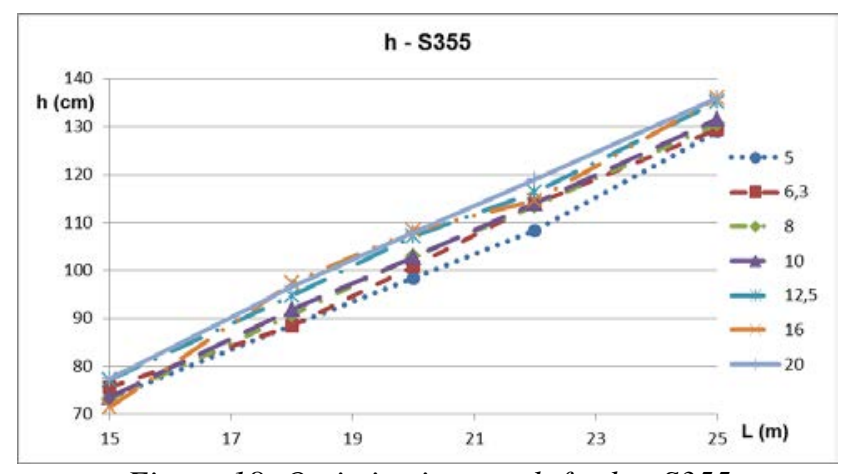

Figure 18. Optimization result for $h-S 355$

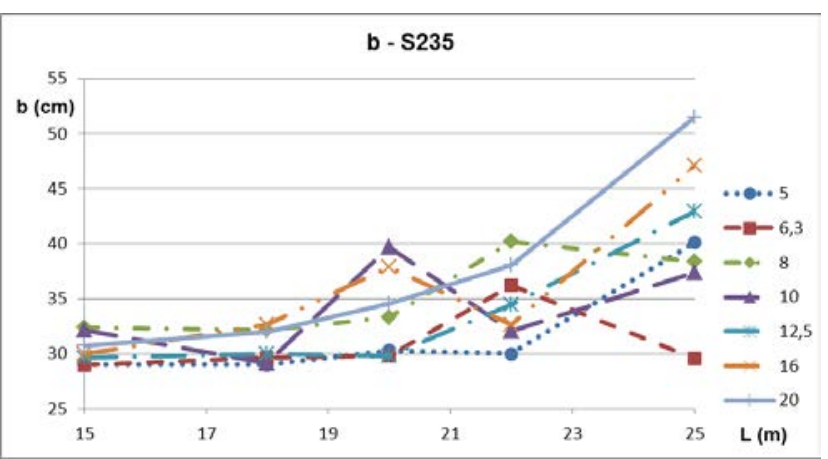

Figure 19. Optimization result for $b-S 235$

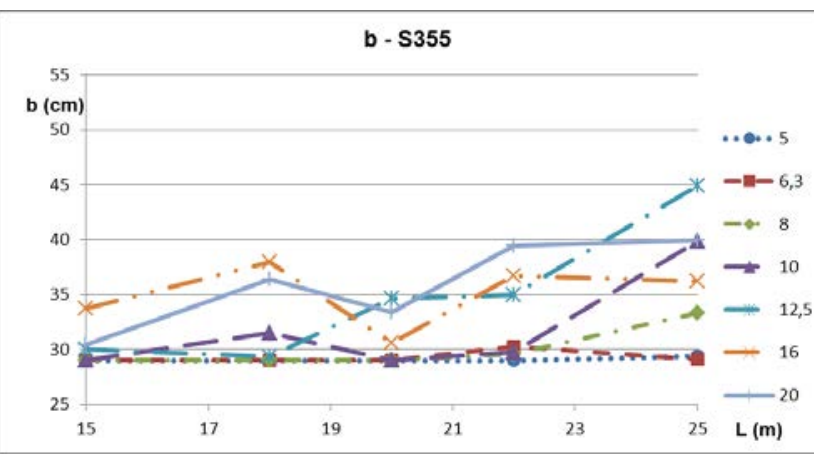

Figure 20. Optimization result for $b-S 355$

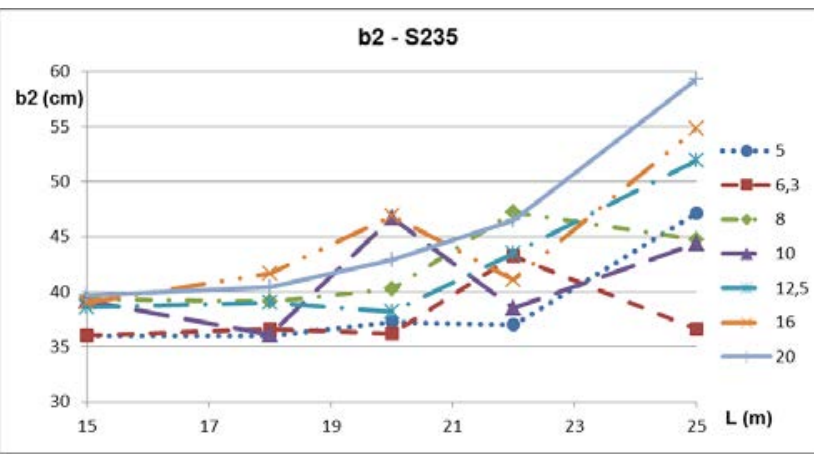

Figure 21. Optimization result for $b_{2}-S 235$

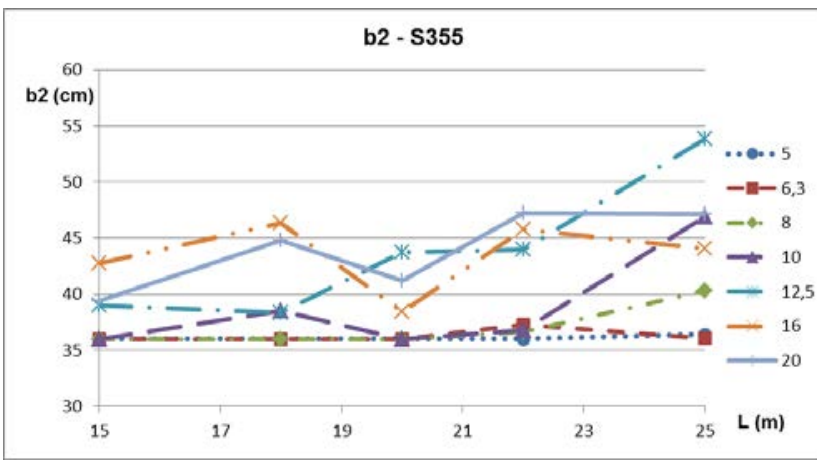

Figure 22. Optimization result for $b_{2}-S 355$
Following tables show the numerical values of optimization results for typical load capacities, span $20 \mathrm{~m}$, material S235 (Table 2) and material S355 (Table 3).

Table 2: Optimization result for $L=20, m-S 235$

\begin{tabular}{|c|c|c|c|c|c|c|c|}
\hline $\begin{array}{c}Q \\
(t)\end{array}$ & $\begin{array}{c}b_{1} \\
(\mathrm{~cm})\end{array}$ & $\begin{array}{c}t_{1} \\
(\mathrm{~mm})\end{array}$ & $\begin{array}{c}t_{2} \\
(\mathrm{~mm})\end{array}$ & $\begin{array}{c}t_{3} \\
(\mathrm{~mm})\end{array}$ & $\begin{array}{c}b \\
(\mathrm{~cm})\end{array}$ & $\begin{array}{c}h \\
(\mathrm{~cm})\end{array}$ & $\begin{array}{c}b_{2} \\
(\mathrm{~cm})\end{array}$ \\
\hline 5 & 26,3 & 6 & 5 & 13 & 30,3 & 98,1 & 37,3 \\
\hline 6,3 & 25,0 & 6 & 6 & 15 & 29,8 & 97,9 & 36,2 \\
\hline 8 & 29,3 & 8 & 5 & 17 & 33,3 & 97,5 & 40,3 \\
\hline 10 & 35,7 & 9 & 5 & 19 & 39,7 & 97,2 & 46,7 \\
\hline 12,5 & 25,0 & 11 & 6 & 24 & 29,8 & 111,7 & 38,2 \\
\hline 16 & 33,8 & 19 & 5 & 28 & 37,8 & 95,3 & 46,8 \\
\hline 20 & 29,7 & 20 & 6 & 31 & 34,5 & 113,4 & 42,9 \\
\hline
\end{tabular}

Table 3: Optimization result for $L=20, m-S 355$

\begin{tabular}{|c|c|c|c|c|c|c|c|}
\hline $\begin{array}{c}Q \\
(t)\end{array}$ & $\begin{array}{c}b 1 \\
(\mathrm{~cm})\end{array}$ & $\begin{array}{c}t 1 \\
(\mathrm{~mm})\end{array}$ & $\begin{array}{c}t 2 \\
(\mathrm{~mm})\end{array}$ & $\begin{array}{c}t 3 \\
(\mathrm{~mm})\end{array}$ & $\begin{array}{c}b \\
(\mathrm{~cm})\end{array}$ & $\begin{array}{c}h \\
(\mathrm{~cm})\end{array}$ & $\begin{array}{c}b 2 \\
(\mathrm{~cm})\end{array}$ \\
\hline 5 & 25,0 & 6 & 5 & 10 & 29,0 & 98,4 & 36,0 \\
\hline 6,3 & 25,0 & 5 & 5 & 11 & 29,0 & 100,8 & 36,0 \\
\hline 8 & 25,0 & 7 & 5 & 13 & 29,0 & 103,0 & 36,0 \\
\hline 10 & 25,0 & 11 & 5 & 15 & 29,0 & 102,8 & 36,0 \\
\hline 12,5 & 30,7 & 12 & 5 & 16 & 34,7 & 107,2 & 43,7 \\
\hline 16 & 25,0 & 8 & 7 & 20 & 30,6 & 108,3 & 38,4 \\
\hline 20 & 27,8 & 9 & 7 & 23 & 33,4 & 107,9 & 41,2 \\
\hline
\end{tabular}

\section{CONCLUSION}

The paper presented optimum dimensions of box section of single-girder bridge crane by GRG2 optimization method, using Excel software package. The criteria of permissible stresses, local stability of plates, lateral stability of the girder, static deflection, dynamic stiffness and production feasibility (distance between the webs) were applied as the constraint functions. The objective function was minimum mass, i.e. minimum cross-sectional area, whereby given constraint conditions were satisfied. Obtained results can be very useful to engineers, especially in the early phase of crane design process, when basic dimensions of the main girder, as most important component, are being defined.

Some conclusions can be made upon previous diagrams:

- thickness $t_{1}$ takes values between $5 \mathrm{~mm}$ and $20 \mathrm{~mm}$ and greater (Fig. 11 and Fig. 12);

- thickness $t_{2}$ takes values between $5 \mathrm{~mm}$ and $7 \mathrm{~mm}$ for S235, i.e. between $5 \mathrm{~mm}$ and $8 \mathrm{~mm}$ for S355 (Fig. 13 and Fig. 14);

- thickness $t_{3}$ has greater values for S235, especially for greater load capacities, in comparison with values obtained for S355; this is due to local influence of wheel pressure (Fig. 15 and Fig. 16);

- height $h$ has almost linear value increase with the increase of crane span, which is best noticeable for material S355 (Fig. 17 and Fig. 18);

- widths $b$ and $b_{2}$ take smaller values for S355 (Figs. 19 22).

This analysis can be further exploited for research of mass reduction in the case where material S275 is used. Beside this, the position of longitudinal stiffener can be varied, according to recommendations [15], in the range of $h / 3-h / 4$ or even adopt value $h / 5$ [8]. Also, this procedure can be expanded with criterion of material fatigue. 
Similar procedure can be carried out for the situation with two rows of longitudinal stiffeners, which is the case for greater spans and load capacities. This is the basis for further investigation and optimization related to material savings and reduction of production costs, which would demand more complex analysis.

\section{ACKNOWLEDGMENT}

A part of this work is a contribution to the Ministry of Science and Technological Development of Serbia funded Project TR35038.

\section{REFERENCES}

[1] J. Farkas, "Optimum design of metal structures", Akademiai Kiado, Chichester, Ellis Horwood, Budapest (Hungary), p. 222, (1984)

[2] J. Farkas, "Economy of higher-strength steels in overhead travelling cranes with double-box girders", Journal of Constructional Steel Research, Vol. 6, pp. 285-301, (1986)

[3] J. Farkas, K. Jarmai, “Analysis and optimum design of metal structures”, Balkema, Rotterdam (Holland), (1997)

[4] J. Farkas, L.M.C. Simoes, K. Jarmai, "Minimum cost design of a welded stiffened square plate loaded by biaxial compression”, Structural and Multidisciplinary Optimization, Vol. 29, Issue 4, pp. 298-303, (2005)

[5] J. Farkas, "Structural optimization as a harmony of design, fabrication and economy”, Structural and Multidisciplinary Optimization, Vol. 30, Issue 1, pp. 66-75, (2005)

[6] J. Farkas, K. Jarmai, J.A. Snyman, "Global minimum cost design of a welded square stiffened plate supported at four corners", Structural and Multidisciplinary Optimization, Vol. 40, Issue 1-6, pp. 477-489, (2010)

[7] F. Faluyi, C. Arum, "Design optimization of plate girder using generalized reduced gradient and constrained artificial bee colony algorithms", International Journal of Emerging Technology and Advanced Engineering, Vol. 2, Issue 7, pp. 304-312, (2012)

[8] K. Jarmai, "Decision Support System on IBM PC for design of economic steel structures applied to crane girders”, Thin-Walled Structures, Vol. 10, pp. 143159, (1990)

[9] K. Jarmai, J. Farkas, "Optimum cost design of welded box beams with longitudinal stiffeners using advanced backtrack method", Structural and Multidisciplinary Optimization, Vol. 21, Issue 1, pp. 52-59, (2001)

[10] K. Jarmai, J.A. Snyman, J. Farkas, G. Gondos, "Optimal design of a welded I-section frame using four conceptually different optimization algorithms", Structural and Multidisciplinary Optimization, Vol. 25, Issue 1, pp. 54-61, (2003)

[11] JUS M.D1.050, "Standardi za dizalice”, Jugoslovenski zavod za standardizaciju, Beograd (Srbija), (1968)
[12] JUS U.E7. /1986, "Standardi za proračun nosećih čeličnih konstrukcija”, Jugoslovenski zavod za standardizaciju, Beograd (Srbija), (1986)

[13] M. Kaufmann, D. Zenkert, P. Wennhage, "Integrated cost/weight optimization of aircraft structures", Structural and Multidisciplinary Optimization, Vol. 41, Issue 2, pp. 325-334, (2010)

[14] D. Ostrić, "Dinamika mosnih dizalica”, Institut za mehanizaciju Mašinskog fakulteta Univerziteta u Beogradu, Beograd, (Srbija), (1998)

[15] D. Ostrić, S. Tošić, "Dizalice", Institut za mehanizaciju Mašinskog fakulteta Univerziteta u Beogradu, Beograd, (Srbija), (2005)

[16] G. Pavlović, M. Gašić, M. Savković, N. Zdravković, "Comparative analysis of local and lateral stability of plates as the constraint functions within optimization of main girder box section of the bridge crane", IMK - 14, Research\&Development, Vol. 18, pp. 11-18, (2012)

[17] G. Pavlović, M. Savković, M. Gašić, R. Bulatović, N. Zdravković, "Optimization of the box section of the main girder of the double beam bridge crane according to the criteria of lateral stability and local stability of plates", Machine Design, Vol.4, No. 4, pp.197-204, (2012)

[18] B.C. Pinca, O.G. Tirian, V.A. Socalici, D.E. Ardeleadn, "Dimensional optimization for the strength structure of a traveling crane”, WSEAS Transactions on Applied and Theoretical Mechanics, Vol. 4, Issue 4, pp. 147-156, (2009)

[19] B.C. Pinca, O.G. Tirian, A. Josan, G. Chete, "Quantitative and qualitative study on the state of stresses and strains of the strength structure of a crane bridge”, WSEAS Transactions on Applied and Theoretical Mechanics, Vol. 5, Issue 4, pp. 231-241, (2010)

[20] M. Savković, M. Gašić, G. Pavlović, R. Bulatović, N. Zdravković, "Optimization of the box section of the main girder of the bridge crane according to the criteria of lateral and local stability of plates", The 7th International Symposium "KOD 2012", Balatonfured (Hungary), 24-26 May 2012, pp. 113120, (2012)

[21] M. Savković, M. Gašić, D. Ćatić, R. Nikolić, Pavlović G., "Optimization of the box section of the main girdre of the bridge crane with the rail placed above the web plate, Structural and Multidisciplinary Optimization, Vol. 47, Issue 2, pp. 273-288, (2013)

[22] M. Savković, G. Pavlović, M. Gašić, N. Zdravković, "Multicriterion optimization of the box section of the main girder of the bridge crane", International Conference on Material Handling, Construction and Logistics "MHCL -12", Belgrade (Serbia), October 2012, p.p. 285-292, (2012)

[23] Technical guide for hoists, SWF Krantechnik $\mathrm{GmbH},(2011)$

[24] R.H. Zuberi, L. Kai, Z. Zhengxing, "Design Optimization of EOT Crane Bridge”, International Conference on Engineering Optimization "Eng Opt 2008”, Rio de Janeiro (Brazil), 01-05 June 2008, pp. 192-201, (2008). 